\title{
Is it getting hot in here? Adjustment of hydraulic parameters in six boreal and temperate tree species after 5 years of warming
}

\author{
KATHERINEA. MCCULLOH ${ }^{1}$, JOSHUA PETITMERMET ${ }^{2}$, ARTUR STEFANSKI ${ }^{3}$, \\ KAREN E. RICE ${ }^{3}$, ROY L. RICH ${ }^{3,4}$, REBECCA A. MONTGOMERY ${ }^{3}$ and PETER B. REICH ${ }^{3,5}$ \\ ${ }^{1}$ Department of Botany, University of Wisconsin-Madison, Madison, WI 53706, USA, ${ }^{2}$ Department of Forest Engineering, \\ Resources, and Management, Oregon State University, Corvallis, OR 97331, USA, ${ }^{3}$ Department of Forest Resources, University of \\ Minnesota, St Paul, MN 55108, USA, ${ }^{4}$ Smithsonian Environmental Research Center, Edgewater, MD 21037, USA, ${ }^{5}$ Hawkesbury \\ Institute for the Environment, University of Western Sydney, Penrith, NSW 2753, Australia
}

\begin{abstract}
Global temperatures (T) are rising, and for many plant species, their physiological response to this change has not been well characterized. In particular, how hydraulic parameters may change has only been examined experimentally for a few species. To address this, we measured characteristics of the hydraulic architecture of six species growing in ambient $\mathrm{T}$ and ambient $+3.4{ }^{\circ} \mathrm{C} \mathrm{T}$ plots in two experimentally warmed forest sites in Minnesota. These sites are at the temperate-boreal ecotone, and we measured three species from each forest type. We hypothesized that relative to boreal species, temperate species near their northern range border would increase xylem conduit diameters when grown under elevated $\mathrm{T}$. We also predicted a continuum of responses among wood types, with conduit diameter increases correlating with increases in the complexity of wood structure. Finally, we predicted that increases in conduit diameter and specific hydraulic conductivity would positively affect photosynthetic rates and growth. Our results generally supported our hypotheses, and conduit diameter increased under elevated $\mathrm{T}$ across all species, although this pattern was driven predominantly by three species. Two of these species were temperate angiosperms, but one was a boreal conifer, contrary to predictions. We observed positive relationships between the change in specific hydraulic conductivity and both photosynthetic rate $(P=0.080)$ and growth $(P=0.012)$. Our results indicate that species differ in their ability to adjust hydraulically to increases in T. Specifically, species with more complex xylem anatomy, particularly those individuals growing near the cooler edge of their range, appeared to be better able to increase conduit diameters and specific hydraulic conductivity, which permitted increases in photosynthesis and growth. Our data support results that indicate individual's ability to physiologically adjust is related to their location within their species range, and highlight that some wood types may adjust more easily than others.
\end{abstract}

Keywords: Boreal Forest Warming at an Ecotone in Danger, boreal-temperate ecotone, conduit diameter, elevated temperature, hydraulic conductivity, saplings

Received 4 February 2016 and accepted 27 February 2016

\section{Introduction}

Global temperatures $(\mathrm{T})$ have been rising since the middle of the last century and are predicted to continue to increase because of the greenhouse effect caused by the anthropogenic consumption of fossil fuels (Melilo, 2014). This $\mathrm{T}$ increase is predicted to occur with concomitant increases in drought frequency and severity. Forest growth and productivity are expected to decline because of these climate shifts, although this will likely vary among sites depending on their location along gradients of relative moisture vs. temperature limitation, and among individuals depending on their location within their climate adapted range (e.g. Reich \&

Correspondence: Katherine A. McCulloh, tel. +1 608890 3042, fax +1 608262 7508, e-mail: kmcculloh@wisc.edu
Oleksyn, 2008; Allen et al., 2009; Ma et al., 2012; Luo \& Chen, 2013, 2015; Chen \& Luo, 2015; Moyes et al., 2015; Reich et al., 2015). These ecosystem level shifts will likely lead to changes in the structure and composition of forests (Chmura et al., 2011), as differences in species' ability to acclimate to new climate conditions will likely lead to local extinctions for some species and/or the establishment of new species.

Given the expected changes in climate, there has been considerable focus on estimating the ability of species to physiologically adjust to higher T. Many of these studies have concentrated on understanding the effect of higher $\mathrm{T}$ on changes in biomass and photosynthetic machinery. In a comprehensive review, Way \& Oren (2010) found plants largely exhibited increases in biomass accumulation at moderate $\mathrm{T}$ increases. They also found that deciduous species' growth tended to be 
more enhanced by higher $\mathrm{T}$ than evergreen species (Way \& Oren, 2010), although this trend may have been largely due to the decline in growth of tropical evergreen species, not in temperate or boreal evergreens. Despite this potentially general trend of increasing biomass, specifics such as where a forest sits on relative moisture vs. temperature gradients and where an individual is located within the overall geographic range of the species likely will result in a wide range of positive, neutral, and negative growth effects (e.g. Reich \& Oleksyn, 2008; Ma et al., 2012; Moyes et al., 2015; Reich et al., 2015). For example, a few studies have observed a decrease in growth or biomass accumulation at higher $\mathrm{T}$ compared to ambient $\mathrm{T}$ (Reich \& Oleksyn, 2008; Wertin et al., 2011; Reich et al., 2015). Importantly, these exceptions were found in populations of Northern Hemisphere trees growing near their southern range limit, which suggests that these populations may have already saturated their ability to acclimate to higher $\mathrm{T}$. Unlike the marked difference in biomass accumulation with changes in T (Way \& Oren, 2010), photosynthetic acclimation has not been as widely observed (e.g. Dillaway \& Kruger, 2010; Bauweraerts et al., 2014; Sendall et al., 2015). This may be because the optimum $\mathrm{T}$ for photosynthesis seems to have a fairly broad range, and may adjust to changes in $\mathrm{T}$ on very short timescales (i.e. days; Sendall et al., 2015).

In contrast to the more labile photosynthetic machinery, the xylem in wood is unchangeable once it is laid down. However, the ability of the hydraulic network to acclimate to increased $\mathrm{T}$ has been studied far less than photosynthetic rates and biomass, and studies on functional changes in trees have largely been carried out using natural gradients in T, moisture, or both (Mencuccini \& Grace, 1995; Maherali \& DeLucia, 2001; Mencuccini \& Bonosi, 2001; Mencuccini, 2003; GeaIzquierdo et al., 2012, 2013; Castagneri et al., 2015; Pfautsch et al., 2016). A limited number of studies have compared hydraulic parameters in greenhouse grown saplings and did not observe changes in the xylem area-specific hydraulic conductivity of plants grown under elevated $\mathrm{T}$ relative to control plants (Phillips et al., 2011; Way et al., 2013). It would be useful to have a better understanding of changes in the xylem with increased $\mathrm{T}$ in a wider range of species, given how tightly coordinated photosynthetic rates are to hydraulic supply (Meinzer et al., 1990; Brodribb \& Feild, 2000; Hubbard et al., 2001; Mencuccini, 2003), and the strong correlations between hydraulic conductance and plant productivity (Brodribb, 2009). These links are strong because without a steady hydraulic supply replacing the water lost to transpiration, the stomata are forced to close to avoid desiccation, which limits photosynthesis.
There are a number of differences we might expect to see between individuals grown under elevated $\mathrm{T}$ compared to ambient $T$. For example, the driving force for water loss from the leaf will necessarily go up unless there is a concurrent rise in absolute humidity as $\mathrm{T}$ increases sufficient to maintain the vapour pressure deficit (VPD), which is considered unlikely (Sherwood \& $\mathrm{Fu}, 2014)$. The responses of individual plants to an increase in VPD are likely to be highly varied, depending on species and site-specific conditions. However, as this driving force increases, plants can either close their stomata to avoid desiccation, or transport more water from their roots to their leaves. If plants close their stomata, they will risk having their leaves approach physiologically dangerous temperatures and limit their ability to photosynthesize. To supply the greater evaporative demand while maintaining stomatal conductance, plants could move more water from a given soil water potential and type by either increasing the hydraulic conductance of their xylem network or lowering the leaf water potential. A permanent increase in the whole-plant hydraulic conductance would require a long-term change in the xylem anatomy in at least one of the following ways: an increase in the lumen diameter of the xylem conduits, more conduits per xylem area, and/or a greater functional sapwood area. Lowering the leaf water potential is potentially a shorter term solution. However, this adjustment may require an increase in leaf cell osmotica (to lower the osmotic potential) and/or may increase the chances of drought-induced embolism propagation throughout the xylem if a concomitant change in the xylem structure is not made.

For some species and habitats, indirect effects of warming could also occur. For example, in seasonally cold environments where even during much of the growing season the rate of metabolic processes may often be limited by low temperatures and/or the inability to acquire nutrients from cold or frozen soils, higher temperatures could result in higher carbon assimilation and growth rates. Furthermore, due to the coupling of carbon acquisition and hydraulics mentioned earlier, it is at least plausible that faster growth rates might be accompanied by wider conduit diameters of new wood.

In the few studies that have examined changes in hydraulic parameters at elevated vs. ambient $\mathrm{T}$, the results have been equivocal. In seedlings grown in controlled environments, tracheid diameters in Pinus ponderosa increased at elevated T (Maherali \& DeLucia, 2000), while vessel diameter in Eucalyptus grandis decreased at temperatures above an optimum of $25{ }^{\circ} \mathrm{C}$ (Thomas et al., 2004, 2007). Using natural gradients, other studies have also found conflicting patterns (Garcia-Gonzalez \& Eckstein, 2003; Fonti et al., 2007; 
Gea-Izquierdo et al., 2012; Voelker et al., 2012). One complication that may cloud results from these studies is the degree to which different species and/or wood types are reliant on conduits produced in the spring for the bulk of their water transport. For example, using vessel dimensions measured on bur oak (Quercus macrocarpa) tree cores taken from living trees and ancient wood (trees that lived $\sim 12000$ years ago that had not fossilized), Voelker et al. (2012) elegantly showed a strong positive relationship between vessel diameter and spring $\mathrm{T}$. When spring $\mathrm{T}$ values are low, conduit expansion seems to be temperature limited and the vessels formed during cooler springs tend to be narrower (Voelker et al., 2012). Ring-porous species, which rely on very wide vessels made early in the growing season for the majority of the water transport in their xylem, may be more sensitive to $\mathrm{T}$ increases than diffuse-porous or coniferous species that make conduits throughout the growing season, when values of $\mathrm{T}$ are usually warm enough to not limit development. Interestingly, this pattern was not observed in $Q$. canariensis by Gea-Izquierdo et al. (2012); however, that species exhibited both ring porosity and semiring porosity, which may explain the difference. The semiring porous nature would result in wide-diameter vessels being made later in the growing season, which may reduce or eliminate the developmental constraint of the ring-porous habit that Voelker et al. (2012) observed.

Measurements of how functional hydraulic parameters, such as hydraulic conductivity, change with increasing $\mathrm{T}$ have also differed among species. In seedlings of two species of Eucalyptus grown at ambient and elevated T, Phillips et al. (2011) found xylem area-specific hydraulic conductivity did not differ in one species and slightly increased at elevated $\mathrm{T}$ in the other (comparing only plants grown at $400 \mathrm{ppm} \mathrm{CO}_{2}$ ). Way et al. (2013) found no differences in specific hydraulic conductivity in seedlings of Populus tremuloides, but did observe increases in root hydraulic conductance at elevated T.

To better understand the physiological responses to increases in $\mathrm{T}$ of species growing at the temperate-boreal ecotone, the Boreal Forest Warming at an Ecotone in Danger (B4WarmED) project initiated warming treatment regimes in 2009. This free-air warming experiment at two sites in northern Minnesota exposes saplings of boreal and temperate species to ambient $\mathrm{T},+1.7^{\circ} \mathrm{C}$ or $+3.4{ }^{\circ} \mathrm{C}$ above ambient (Rich et al., 2015). Previous results showed photosynthetic rates increased in species near their northern range limit (i.e. temperate species) while those nearer their southern range limit (i.e. boreal species) did not (Reich et al., 2015). However, in the six angiosperm species examined by Reich et al. (2015), Sendall et al. (2015) did not find differences in their ability to acclimate the $\mathrm{T}$ optimum for their maximum photosynthetic rate. In contrast, acclimation of respiration to $\mathrm{T}$ variation was considerable among all 10 species, but was stronger for evergreen gymnosperms than deciduous angiosperms (Reich et al., 2016). Thus, depending upon the response metric that was assessed, responses either did not differ or varied in relation to different attributes (biogeographic range, phylogeny); clearly, more work is needed to determine whether climate warming responses of other parameters differ among species, and if so, in what pattern and why.

For the work described here with three angiosperm and three gymnosperm species, our goal was to characterize the xylem anatomical and hydraulic properties of branches from species growing in the ambient and $+3.4{ }^{\circ} \mathrm{C}$ elevated $\mathrm{T}$ treatments. We hypothesized that temperate species near the northern end of their range would be better able to increase lumen diameters when grown under elevated $\mathrm{T}$ compared to boreal species. This increase in lumen diameter should increase the specific hydraulic conductivity of the wood, a response mechanistically consistent with increased photosynthesis. We also predicted that the angiosperm species (two temperate and one boreal), which have more complex xylem and generally wider diameter conduits, would adjust their xylem parameters more than the conifers. Ancillary to this, we expected that the one ring-porous species ( $Q$. macrocarpa), which at ambient $T$ has the widest conduits, would exhibit the greatest increase in vessel lumen diameter at elevated $\mathrm{T}$ because of the dependence of vessel development on spring $\mathrm{T}$ (Voelker et al., 2012). Because of our expectation of a positive correlation between conduit diameter and the ability for species to widen their conduit diameters under elevated $\mathrm{T}$, we expected that a plot of conduit diameter at ambient vs. elevated $\mathrm{T}$ would have a slope greater than one. Furthermore, given the well-established relationships between hydraulic parameters and photosynthesis and growth (Meinzer et al., 1990; Brodribb \& Feild, 2000; Hubbard et al., 2001; Mencuccini, 2003), we predicted that increases in conduit diameter and specific hydraulic conductivity would positively affect photosynthetic rates and growth. Finally, we expected that wider diameter conduits may lead to lower wood density under elevated $\mathrm{T}$ and that this may also lead to greater sapwood hydraulic capacitance, which tends to correlate with wood density (Meinzer et al., 2008; McCulloh et al., 2014).

\section{Materials and methods}

\section{Site description and sample collection}

The B4WarmED experiment is located at two sites, the Cloquet Forestry Center (CFC), Cloquet, MN, USA $\left(46^{\circ} 40^{\prime} 46^{\prime \prime} \mathrm{N}\right.$, 
$92^{\circ} 31^{\prime} 12 \mathrm{~W} ; 4.5^{\circ} \mathrm{C}$ mean annual temperature), and a higher latitude site at the Hubachek Wilderness Research Center

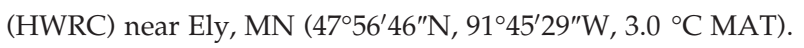
The two sites are approximately $150 \mathrm{~km}$ apart within the temperate forest-boreal forest ecotone of northern Minnesota (Rich et al., 2015).

At each site, half of the experimental plots are located within a clear-cut, open habitat and the other half are in a closed $(\sim 5-10 \%$ of full sunlight) habitat with an intact overstory of 40-60-year-old aspen-birch-fir. For this study, only plots from the closed habitat were used.

Each site contains three blocks within the closed canopy, with two replicates of ambient temperature and ambient $+3.4{ }^{\circ} \mathrm{C}$ temperature circular plots with an area of $7.1 \mathrm{~m}^{2}$. Warmed plots have simultaneous above and below ground warming, manipulated through ceramic infrared heaters and buried resistance cables in soils. Target warming temperatures were achieved through a feedback control system used throughout the growing season, approximately 8 months of the year. For a complete review of the experimental design and warming technique, see Rich et al. (2015). Our six selected study species include two boreal conifers [Picea glauca (Moench) Voss, Abies balsamea (L.) Mill], one temperate conifer (Pinus strobus L.), two temperate angiosperms (Q. macrocarpa Michx., Acer saccharum Marshall), and one boreal angiosperm (P. tremuloides Michx.). Sapling height and diameters are shown in Table S1.

Over the course of 6 weeks in late April-June of 2014, we randomly selected eight individuals (where available) of six tree species within the ambient and the ambient $+3.4{ }^{\circ} \mathrm{C}$ warming treatments at each site (eight individuals $\times$ six species $\times$ two heat treatments $\times$ two sites). Low survival rates resulted in reduced numbers of $P$. tremuloides. For each individual sapling, we harvested the entire stem. At time of harvest, saplings had been exposed to 5 years of experimental warming and leaf-out had not yet occurred. After harvesting, stems were wrapped in damp paper towels, shipped to Madison WI, and refrigerated until hydraulic measurements were made. All measurements were completed within 1 week of harvest.

\section{Hydraulic conductivity measurements}

Stem segments were cut from the main stem to assess the hydraulic conductivity. Selection of appropriate segments was based on finding internodes at least $2 \mathrm{~cm}$ long and 2 years old. This length restriction was only a limitation for Picea, which had very short internodes and segments that were long enough were often three or 4 years old. The length of segments used for other species averaged $5 \mathrm{~cm}$. After removing segments from the main stem by cutting them underwater with clippers, their axial ends were recut underwater with a fresh razor blade. Samples were then submerged in an aqueous solution of $20 \mathrm{~mm} \mathrm{KCl}$ that had been filtered through $0.2 \mu \mathrm{m}$ filter paper, and a partial vacuum was applied overnight to remove emboli.

After removing the emboli, maximum hydraulic conductivity was determined by measuring the rate at which water flowed through the segment to a balance. Flow was induced by a pressure head of 4-6 kPa. Hydraulic conductivity was expressed per cross-sectional xylem area (ks).

\section{Capacitance measurements}

The ability of the wood to store water was determined by measuring moisture release curves. Short chunks of wood ( $\sim 1 \mathrm{~cm}$ in length) adjacent to or in the internode immediately basal to the segment used for hydraulic conductivity measurements were cut from the main stem, their bark was removed, and they were submerged overnight in distilled water held under a partial vacuum. The saturated samples were then blotted dry using a paper towel, the saturated mass (Ms) measured and the samples placed into chambers containing screen-cage thermocouple psychrometers (83 series; JRD Merrill Specialty Equipment, Logan, UT, USA) as described elsewhere (Meinzer et al., 2003; McCulloh et al., 2014). Wood density was calculated as saturated volume, which was determined by the mass of water displaced when the stem segment was submerged, divided by oven dried mass, which was determined after drying in oven for 2-3 days at $100{ }^{\circ} \mathrm{C}$.

By comparing the cumulative water lost vs. sample water potential (a moisture release curve), the capacitance was calculated from the slope of the initial, nearly linear portion of the curve. The beginning of the regression used to calculate capacitance was forced through the origin, because it is physically impossible to have water released at $0 \mathrm{MPa}$. The end point on the regression was the inflection point or point of diminishing returns on the water release curve, after which the amount of water released per decline in water potential $(\Psi)$ levelled out. This point was determined by plotting $-1 / \Psi$ vs. the cumulative water released and developing a regression using the points with low water released. Subsequent data points were added (i.e. in order of decreasing $-1 / \Psi$ on the $x$-axis) to the regression until the coefficient of variation declined. The data point at which the regression had the maximum coefficient of variation was used as the end point in the moisture release curve regression used to calculate capacitance.

\section{Stem anatomy}

To compare the physiological measurements with the anatomy of the stems, cross sections were made by hand of two stems from each treatment and site. Sections were made on segments used for hydraulic conductivity measurements. After mounting the sections in glycerin, they were imaged on a Nikon Eclipse Ci microscope (Nikon Instruments Inc, Tokyo, Japan) using a Nikon DS-Fi2 camera. Images were made of xylem sectors that ran from the bark to the pith. Using the 'polygon' function in IMAGEJ software (National Institutes of Health, Bethesda, MD, USA), the lumen area of vessels or tracheids were measured along this radial transect to capture the developmental range present. Additional radial transects were measured until at least 100 vessels or tracheids from each branch were measured. The lumen areas were converted to diameter by assuming that the shape of the conduit was a circle. The hydraulically weighted mean diameter (Dh) was calculated for each stem sampled for anatomy. This was 
determined as $\mathrm{Dh}=\left(\sum D^{4} / n\right)^{1 / 4}$ where $D$ is the individual conduit diameter measurement and $n$ is the number of measurements made per stem segment.

\section{Data analyses}

Comparisons of variables across treatment, species and sites were made using RSTUDIO (R Development Team 2014). For all comparisons across factors, analysis of variance (ANOVA) tests were run using the aov function in two ways. First, treatment and species were treated as fixed effects and site as a random effect. Second, all effects were treated as fixed. In each case, the results were the same (if $P$-values did differ, they did not change the result from significant to not significant or vice versa), so results are only shown from the first approach. Furthermore, the first approach is more appropriate because only two sites were used. The conduit diameter data exhibited a slightly skewed distribution, but ANOvA tests are very robust to shifts in distribution (Glass et al., 1972), and our results did not differ when we compared log-transformed data. Thus, we only present untransformed data. When significant results were observed, Tukey's HSD tests were used post hoc to determine differences between treatments or species. Linear relationships among measured variables were made using the standard major axis (SMA) approach. Slopes for the linear relationships and differences among them were tested for using SMATR (Warton et al., 2006; http://www.bio.mq.edu.au/ecology/SMATR/). To compare percentage changes in conduit diameters and ks under elevated $\mathrm{T}$ to percentage changes in photosynthetic rate and growth, we used data from Reich et al. (2015) for our six species.

\section{Results}

Our results indicated that some of the studied species adjusted their hydraulic network both anatomically and functionally to the elevated $\mathrm{T}$ treatment. However, not all parameters we examined were different between the treatments. The slope of the decline in frequency of conduits with increasing conduit diameter did not differ among treatments, but was different between angiosperm and conifer species $(P<0.001$, Fig. 1$)$. Across all species, the heat treatment did result in wider conduit diameters than the ambient treatment $(P<0.001$, Table 1). Post hoc tests indicated that three (Abies, Acer, and Quercus) of the six species had wider conduits in the heated treatment than ambient $(P<0.001$, Table 2; Fig. 2$)$. The boreal angiosperm species (Populus) also had marginally wider conduits at elevated T $(P=0.07$, Table 2$)$. Two of the three conifer species (Pinus and Picea) had tracheid diameters that did not differ among treatments. Similarly, the hydraulically weighted diameters $(\mathrm{Dh})$ were wider in the heated plants than in ambient. Post hoc tests revealed that the differences in $\mathrm{Dh}$ were driven by differences between treatments in Acer and Quercus (Table 3, $P<0.004$ for each species).
When the mean conduit diameter was compared across treatment for each species and site, the impact of the treatment was evident (Fig. 3). The slope of this relationship was $>1(P=0.021)$, but the intercept did not differ from $0(P=0.15)$, indicating that species with wider conduits at ambient $\mathrm{T}$ increased their conduit diameters to a greater extent at elevated $\mathrm{T}$ than those with narrow conduits.

When the frequency distribution of the conduit diameters from the ambient vs. elevated T treatments is compared, differences between the Abies and the two angiosperm species were evident (Fig. 4). In the Abies, the increase in tracheid diameter is caused by a greater proportion of large diameter tracheids in size classes that were present in the ambient treatment as well, not a shift towards a more right-skewed distribution. In contrast, the frequency distributions of the angiosperm species indicated that wider vessels were formed in the elevated $\mathrm{T}$ treatment than in the ambient, which created a more right-skewed distribution. Interestingly, these two angiosperm species were temperate species near the northern edge of their range, while Abies is a boreal species growing near its southern range limit. Populus, the boreal angiosperm species we examined, had conduit diameters that did not differ between treatments.

The increase in conduit diameter under heated conditions (Figs 3 and 4) resulted in higher values of specific hydraulic conductivity in warmed treatment among species $(P=0.02)$. However, post hoc tests indicated this pattern was largely driven by differences in Quercus $(P=0.01$; Fig. 5). Hydraulic capacitance did not differ consistently between treatments within a species (Table 3). There also were not significant differences within species in their wood density between treatments. However, it is worth noting that for all species,

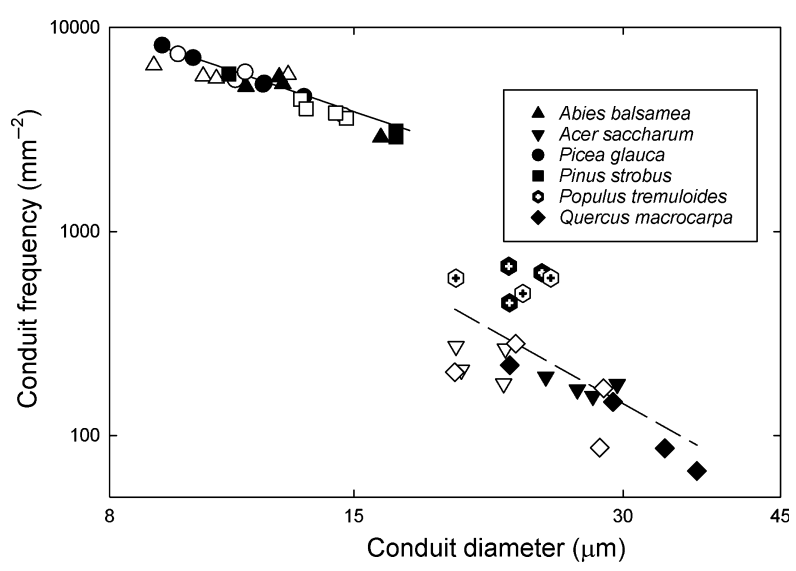

Fig. 1 The decline in conduit frequency as conduit diameter increases for six species growing at ambient (open symbols) and $+3.4{ }^{\circ} \mathrm{C}$ (closed symbols). 
Table 1 Results from a mixed effect ANOVA analysis of conduit diameter. In this analysis, treatment and species were fixed factors and site was a random factor

\begin{tabular}{lrrrrr}
\hline $\begin{array}{l}\text { Source of } \\
\text { variance }\end{array}$ & df & \multicolumn{1}{c}{ SS } & Mean Sq & $F$ value & $P$-Value \\
\hline Treatment & 1 & 5881 & 5881 & 53.0 & $<0.001$ \\
Species & 5 & 163961 & 32792 & 95.0 & $<0.001$ \\
Site & 1 & 3279 & 3279 & 529.9 & $<0.001$ \\
Treatment $\times$ & 5 & 9854 & 1971 & 31.9 & $<0.001$ \\
species & & & & & \\
Residuals & 4664 & 286602 & 62 & & \\
\hline
\end{tabular}

Table 2 Results from post hoc Tukey's HSD tests comparing species $\times$ treatment effects on differences in mean conduit diameter

\begin{tabular}{lc}
\hline Abies balsamea & $<0.001$ \\
Acer saccharum & $<0.001$ \\
Picea glauca & 0.43 \\
Pinus strobus & 0.90 \\
Populus tremuloides & 0.07 \\
Quercus macrocarpa & $<0.001$ \\
\hline
\end{tabular}

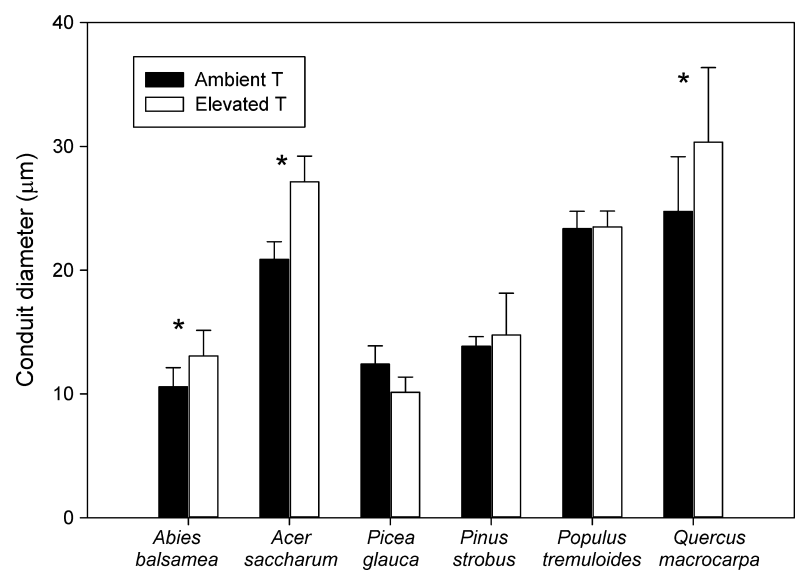

Fig. 2 Mean conduit diameter from branches of saplings growing in ambient plots and $+3.4{ }^{\circ} \mathrm{C}$ plots. ANOVA results indicated conduit diameters increased in elevated $\mathrm{T}$, and post hoc tests indicated this result was driven by differences in three species (indicated by asterisks). Error bars indicate standard errors. See text for specific results.

except Quercus, the wood density in the elevated T stems was either equal to or greater than the control stems. For Quercus, wood density declined in the heated stems relative to the control segments.

We hypothesized that across species, changes in hydraulic properties due to the warming treatment would be related to species-specific differences in changes of photosynthetic carbon gain and growth. We found positive, but not significant, relationships between the percentage change in conduit diameter at elevated $\mathrm{T}$ and the percentage changes in photosynthetic rate and growth (data not shown). However, when we compared these parameters to the percentage of the specific hydraulic conductivity at ambient $\mathrm{T}$ that plants grown at elevated $\mathrm{T}$ achieved (i.e. 100\% indicates no change between treatments; Fig. 6), we found a marginal positive relationship with the change in photosynthetic rate $(P$-value $=0.080)$ and a significant positive relationship with change in growth rate $(P$-value $=0.012)$.

\section{Discussion}

Unlike the large number of studies that have examined changes in biomass and photosynthesis under different T regimes (e.g. Tjoelker et al., 1998; Teskey \& Will, 1999; Dillaway \& Kruger, 2010; Sendall et al., 2015), few studies have focused on how different species' hydraulic architecture shifts under warmer climates (but see Phillips et al., 2011; Way et al., 2013). Those studies did not find drastic changes in many hydraulic parameters, but they did find substantial changes in some. In our study, the observed changes were consistent with increases in growth (Fig. 6). We found that under elevated T, conduits were generally wider and this caused an increase in hydraulic conductivity among species. Similar to our findings for $P$.tremuloides, which did not exhibit an increase in hydraulic conductivity in the heat treatment of our study, Way et al. (2013) also found no change in this parameter in branches, but did observe increases in hydraulic conductance of leaves and roots in heated vs. ambient aspen. This distinction highlights the multitude of ways that plants could adjust their hydraulic network to changes in T. Interestingly, Phillips et al. (2011) did find differences in leaf water potential in heated vs. control plants, but found elevated temperatures resulted in more negative water potentials in a fast-growing species of Eucalyptus and less negative water potentials in a slower-growing congener.

Our results indicated some degree of support for our hypotheses. We predicted that the temperate species, which would be growing near their northern range limit at our sites, would be better able to adjust their hydraulic network to warmer temperatures. Greater adjustment of hydraulic parameters to high temperatures has been observed in individuals from more warm-adapted populations of two desert shrubs (Comstock, 2000). In support of this expectation, two of the three species that had significantly wider conduits in the heat treatment were temperate species (Acer and Quercus), and the only species to significantly increase specific hydraulic conductivity was the temperate species, $Q$. macrocarpa. These results also generally support our hypothesis that the angiosperms would more 
Table 3 The hydraulically weighted mean conduit diameter, wood capacitance and density of branches from saplings grown in plots that were at ambient $\mathrm{T}$ or $+3.4{ }^{\circ} \mathrm{C}$. Asterisks indicate instances in which the hydraulic diameter differed between treatments for a species $(P$-value $<0.005)$. Capacitance means were averaged between sites. Other values are means among all individuals. Means are shown \pm standard deviations

\begin{tabular}{|c|c|c|c|c|c|c|}
\hline \multirow[b]{2}{*}{ Species } & \multirow{2}{*}{$\begin{array}{l}\begin{array}{l}\text { Hydraulic } \\
(\mu \mathrm{m})\end{array} \\
\text { Amb T }\end{array}$} & diameter & \multicolumn{2}{|c|}{$\begin{array}{l}\text { Capacitance } \\
\left(\mathrm{kg} \mathrm{m}^{-3} \mathrm{MPa}^{-1}\right)\end{array}$} & \multicolumn{2}{|c|}{ Wood density $\left(\mathrm{g} \mathrm{cm}^{-3}\right)$} \\
\hline & & $+3.4{ }^{\circ} \mathrm{C}$ & Amb T & $+3.4^{\circ} \mathrm{C}$ & Amb T & $+3.4{ }^{\circ} \mathrm{C}$ \\
\hline Abies balsamea & $12 \pm 2$ & $14 \pm 2$ & $343 \pm 23$ & $207 \pm 55$ & $0.58 \pm 0.1$ & $0.61 \pm 0.1$ \\
\hline Acer saccharum & $24 \pm 1$ & $31 \pm 3^{*}$ & $437 \pm 64$ & $330 \pm 9$ & $0.56 \pm 0.1$ & $0.56 \pm 0$ \\
\hline Picea glauca & $14 \pm 2$ & $11 \pm 1$ & $179 \pm 22$ & $150 \pm 2$ & $0.62 \pm 0.1$ & $0.64 \pm 0.1$ \\
\hline Pinus strobus & $15 \pm 1$ & $16 \pm 4$ & $223 \pm 89$ & $335 \pm 33$ & $0.43 \pm 0.1$ & $0.47 \pm 0.1$ \\
\hline Populus tremuloides & $29 \pm 3$ & $26 \pm 2$ & $485 \pm 34$ & $430 \pm 90$ & $0.41 \pm 0$ & $0.47 \pm 0.1$ \\
\hline Quercus macrocarpa & $35 \pm 7$ & $41 \pm 8^{*}$ & $300 \pm 9$ & $313 \pm 39$ & $0.74 \pm 0$ & $0.72 \pm 0.1$ \\
\hline
\end{tabular}

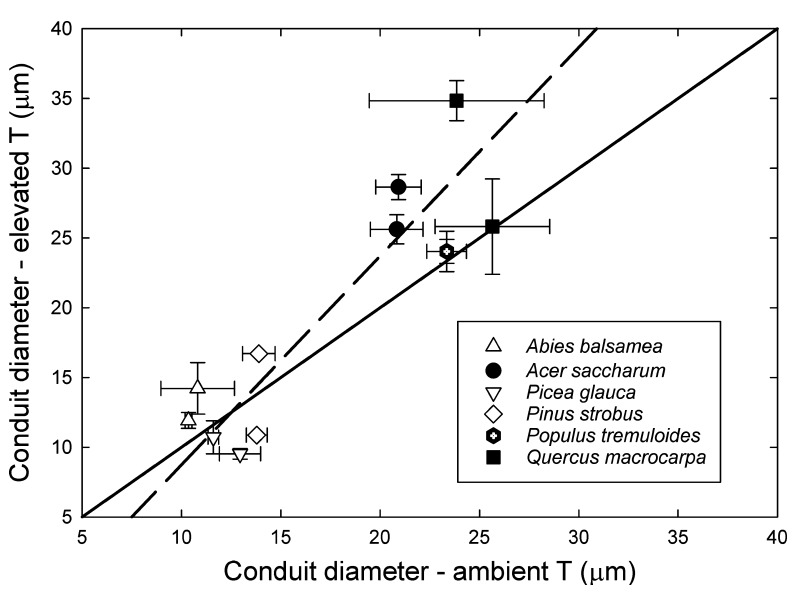

Fig. 3 Mean conduit diameter for branches of trees growing at ambient $\mathrm{T}$ and $+3.4{ }^{\circ} \mathrm{C}$. Separate symbols for species are shown for each of the two sites. The slope of the SMA relationship (dashed line) was significantly greater $(P=0.021)$ than the $1: 1$ line (solid line).

readily adjust their anatomy, and thereby their physiology. The temperate conifer ( $P$. strobus) did not exhibit changes in conduit diameter or specific hydraulic conductivity in the heat treatment. However, despite its more complex wood anatomy, the boreal angiosperm ( $P$. tremuloides) only exhibited a slight increase in conduit diameter $(P=0.07)$ and did not differ in its hydraulic function. We had also hypothesized that by extension of the predicted differences between groups (conifer vs. angiosperm) and home ranges (temperate vs. boreal), that the relationship between conduit diameter at ambient $\mathrm{T}$ and elevated $\mathrm{T}$ would have a slope $>1$, which was supported (Fig. 3).

We had also hypothesized that the changes we predicted in the anatomy and hydraulic physiology at elevated $\mathrm{T}$ would lead to differences in photosynthesis and growth across species. This hypothesis was supported by the relationships with specific hydraulic conductivity (Fig. 6), but not conduit diameter. It is somewhat surprising that we did not observe stronger relationships between conduit diameter and changes in photosynthetic rate and growth, given the strong dependence of hydraulic conductivity on it (Tyree \& Zimmermann, 2002). Hydraulic conductance is also proportional to conduit frequency, but there was not a difference in the relationship between conduit diameter and frequency between treatments (Fig. 1). Other factors, such as pit membrane conductance or conduit length, may have influenced hydraulic conductivity independently of conduit diameter disrupting the expected relationship.

Our final hypothesis was that higher growth $\mathrm{T}$ would lead to lower wood density because of the wider conduit diameters and that this reduction in wood density would result in greater sapwood capacitance values. Neither of these hypotheses were supported. This is not particularly surprising given the complexity of wood and that shifts in one cell type do not necessarily translate to morphological and functional differences at the tissue scale (Lachenbruch \& McCulloh, 2014).

The necessary increase in VPD that would occur with a rise in $\mathrm{T}$ and no increase in relative humidity could result in changes that we were unable to measure, given the limitations of the timing of the harvest to early spring (before leaf-out). For example, for the species we measured that did not adjust their xylem cross-sectional area-specific conductivity, they may have decreased the leaf area to sapwood area ratio or reduced their leaf water potential. Either of these solutions could increase the amount of water supplied to a given leaf area and replace the higher amounts of water lost through transpiration. Although Way et al. (2013) did not observe significant differences in leaf water potentials between treatments, they did observe a decrease in the leaf area to sapwood area ratio in heated $P$. tremuloides. They also found heated plants had a more negative turgor loss point, which is consistent with maintaining a more negative leaf water potential. 


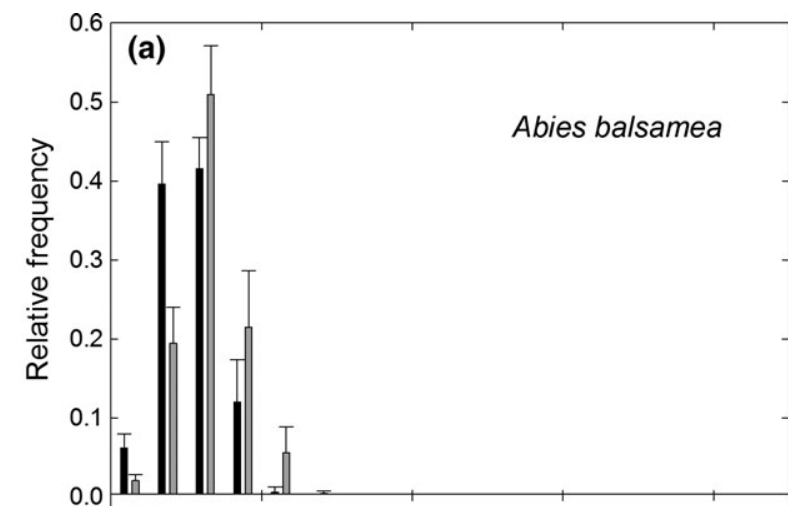

(b)

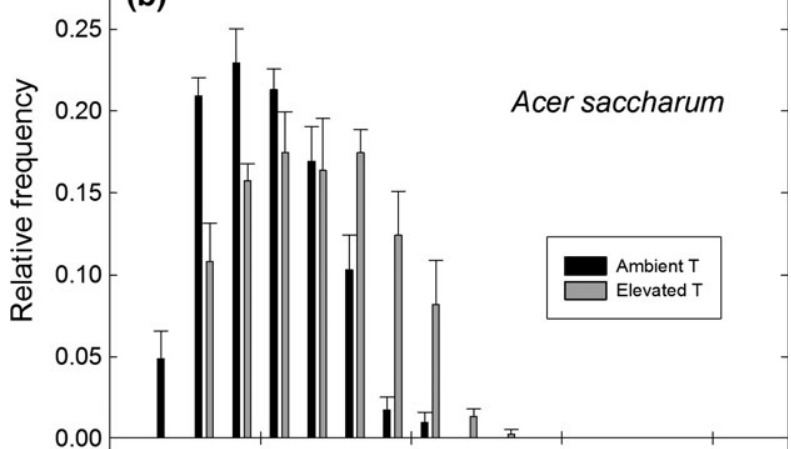

(c)

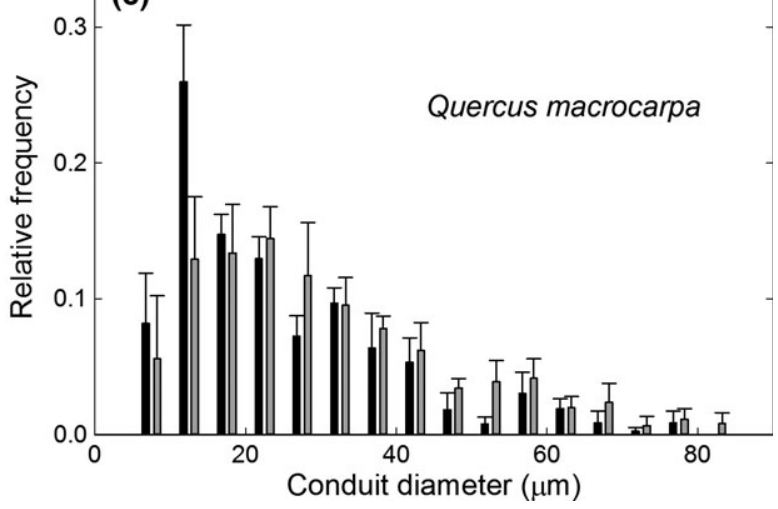

Fig. 4 Relative frequency distributions of conduit diameters in branches of (a) Abies balsamea, (b) Acer saccharum and (c) Quercus macrocarpa grown at ambient temperature and $+3.4{ }^{\circ} \mathrm{C}$. The heat treatment resulted in wider conduits than ambient in these three species.

For the three species that exhibited significant increases in conduit diameter (Abies, Acer, and Quercus), the differences in distribution of conduit diameters between Abies and the two angiosperm species were noteworthy (Fig. 4), because they may indicate that species with narrower diameters at ambient $\mathrm{T}$ are less able to increase conduit size (Fig. 3). For Abies, the range of tracheid diameters present in the branches of the heated plants did not exceed that of the control trees. In fact, the range of diameters exhibited by the ambient treatment plants exceeded the heated plants. The increase in

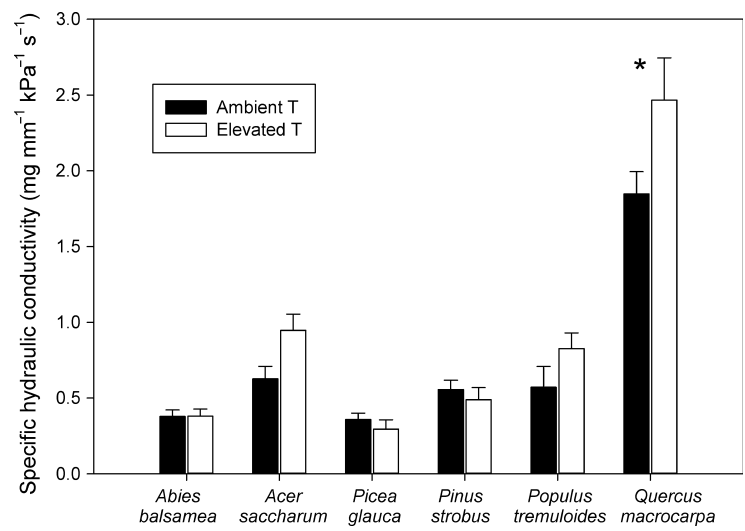

Fig. 5 Hydraulic conductivity expressed on a stem cross-sectional area basis for individuals from six species grown at ambient $\mathrm{T}$ and ambient $+3.4{ }^{\circ} \mathrm{C}$. Comparing all species, individuals grown at elevated $\mathrm{T}$ had higher specific hydraulic conductivity, but post hoc tests revealed that was largely driven by differences in Quercus macrocarpa.

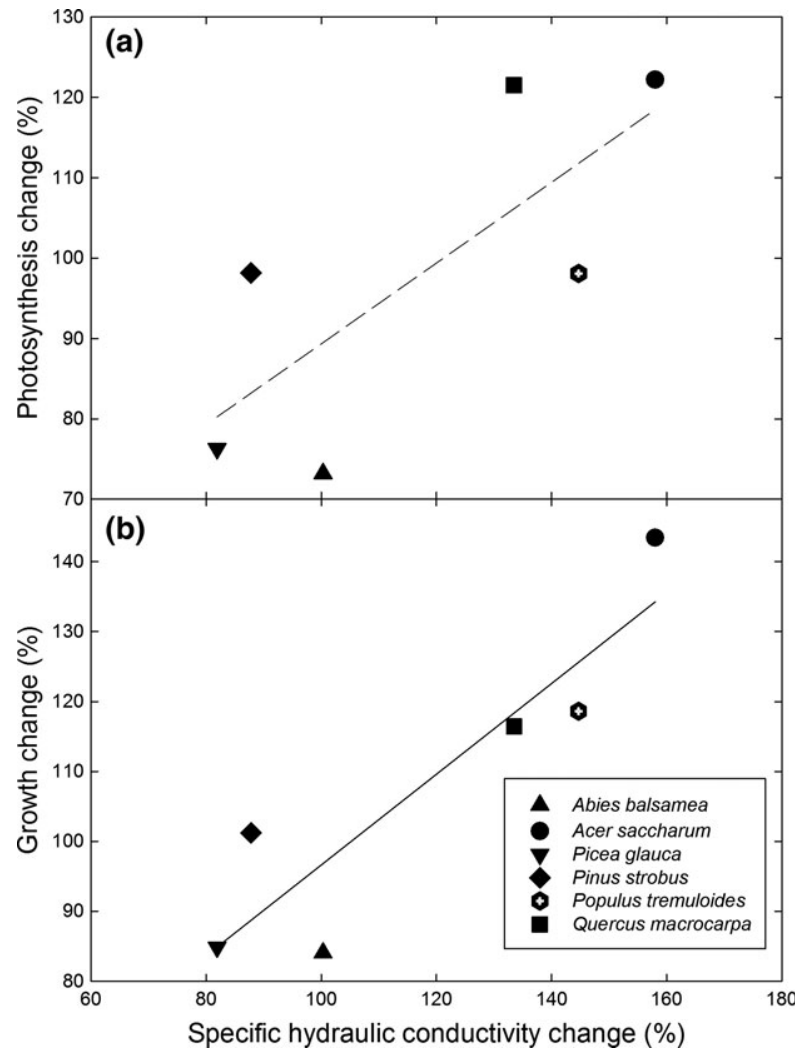

Fig. 6 The percentage changes in photosynthesis (a) and growth (b) vs. the percentage change in specific hydraulic conductivity. Both photosynthesis and growth were positively related to conductivity $(P$-value $=0.080$ and 0.012 , respectively).

mean diameter was solely the result of shifts in the frequency of conduit diameters. In contrast, for both Acer and Quercus, the heat treatment branches exhibited 
vessel diameters that were wider than in the ambient trees (i.e. the distributions became more right skewed in the heat treatment samples). This distinction between the conifers and angiosperms may reflect the differences in the complexity of the wood types. Conifer wood is essentially made up of one cell type (tracheids) with very little $(\sim 5 \%)$ cross-sectional area devoted to ray parenchyma and, in some species, resin canals. For tracheid lumens to become larger, either the ratio of the lumen diameter to wall thickness needs to increase (Pittermann et al., 2006), or some newly formed tracheids need to expand their lumen diameters rapidly and displace neighbouring tracheids. The latter is analogous to how angiosperm wood develops wide-diameter vessels (Esau, 1953), but does not appear to occur in conifer wood. The former can occur, but would also result in lower resistance to drought-induced embolisms (Pittermann et al., 2006), which may be problematic.

A second, but not mutually exclusive, explanation for the difference observed in the conduit diameter ranges of heated vs. ambient stems among species (Fig. 4) is that the boreal species were more limited by high temperatures during development than the temperate species. These species were growing near the southern, warmer end of their range, while the temperate species were near the northern, colder end of their range. The warmer temperatures may have permitted more rapid expansion while the conduits were in the cambial zone (Anfodillo et al., 2012). This increase in vessel diameter with higher $\mathrm{T}$ has been observed before in the oak species also examined here (Voelker et al., 2012). This explanation fails to fully explain the results for our temperate Pinus species, but it may be that the conifer's response was limited by its simpler xylem tissue.

It should also be noted, our hypothesis that the heated plants would increase their conduit diameters simplistically ignores the trade-offs associated with such a change. Not only would the conifers potentially become less resistant to drought-induced hydraulic failure (Pittermann et al., 2006), but all species may become more susceptible to freezing-induced embolisms. This is because the air in bubbles that form when water in wider conduits freezes is more likely to remain partially undissolved when the ice thaws. Narrower conduits tend to have smaller bubbles, which more readily dissolve back into solution and are thus safer from loss of function after freeze-thaw cycles (Davis et al., 1999). Growing at the latitudes of northern Minnesota, the temperate and boreal species we examined would face opposing selective pressures to increase conduit diameter to maximize hydraulic conductance while limiting conduit diameter to avoid embolism induced by freeze-thaw cycles. Ring-porous species solve this dilemma by only relying on the earlywood conduits from the most recent growth ring because the conduits from previous years have embolized during freeze-thaw cycles. Indeed, the ring-porous species examined here, Quercus, exhibited significant increases in conduit diameter and hydraulic conductivity. These anatomical and physiological shifts at higher $\mathrm{T}$ facilitated greater photosynthetic rates and growth.

Despite the large number of studies that have been conducted on how various aspects of plant metabolism may change under elevated $T$, we still know very little about likely changes in the xylem network. Given the timing of the harvest of our plants, we were unable to test for changes in crucial aspects of hydraulic adjustment (e.g. changes in vulnerability to drought-induced embolism and leaf area to sapwood area ratios). However, we did observe intriguing shifts in anatomical and functional parameters in some of the species we examined, and those correlated with changes in photosynthetic physiology and growth. Further studies should investigate more fully whether limitations in conduit diameter increases are related to wood type, species range, or both.

\section{Acknowledgements}

The authors are grateful to William Arrett, Colin Sayre, Beth Rutila, and Chelsey Baranczyk for assistance with collection in the field and sample measurement, and to Cindy Buschena for organizational assistance. The authors are also appreciative of Cécile Ané and Bret Larget for statistical advice. The comments of two anonymous reviewers greatly improved the manuscript. Funding provided by: U.S. Department of Energy Program on Ecological Research 385 Grant No. DE-FG02-07ER64456, Wilderness Research Foundation, and the University of WisconsinMadison Graduate School and College of Letters and Science.

\section{References}

Allen CD, Macalady A, Chenchouni H et al. (2009) A global overview of drought and heat-induced tree mortality reveals emerging climate change risks for forests. Forest Ecology and Management, 259, 660-684.

Anfodillo T, Deslauriers A, Menardi R, Tedoldi L, Petit G, Rossi S (2012) Widening of xylem conduits in a conifer tree depends on the longer time of cell expansion downwards along the stem. Journal of Experimental Botany, 63, 837-845.

Bauweraerts I, Mannaerts TBHL, Wertin TM, McGuire MA, Teskey RO, Steppe K (2014) Elevated $\left[\mathrm{CO}_{2}\right]$ and growth temperature have a small positive effect on photosynthetic thermotolerance of Pinus taeda seedlings. Trees, 28, 1515-1526.

Brodribb TJ (2009) Xylem hydraulic physiology: the functional backbone of terrestrial plant productivity. Plant Science, 177, 245-251.

Brodribb TJ, Feild TS (2000) Stem hydraulic supply is linked to leaf photosynthetic capacity: evidence from New Caledonian and Tasmanian rainforests. Plant, Cell $\mathcal{E}$ Environment, 23, 1381-1388.

Castagneri D, Petit G, Carrer M (2015) Divergent climate response on hydraulicrelated xylem anatomical traits of Picea abies along a 900-m altitudinal gradient. Tree Physiology, 00, 1-10.

Chen H, Luo Y (2015) Net aboveground biomass declines of four major forest types with forest ageing and climate change in western Canada's boreal forests. Global Change Biology, 21, 3675-3684.

Chmura DJ, Anderson PD, Howe GT et al. (2011) Forest responses to climate change in the northwestern United States: ecophysiological foundations for adaptive management. Forest Ecology and Management, 261, 1121-1142. 
Comstock JP (2000) Variation in hydraulic architecture and gas-exchange in two desert sub-shrubs, Hymenoclea salsola (T. \& G.) and Ambrosia dumosa (Payne). Oecologia, 125, 1-10.

Davis SD, Sperry JS, Hacke UG (1999) The relationship between xylem conduit diameter and cavitation caused by freezing. American Journal of Botany, 86, 1367-1372.

Dillaway DN, Kruger EL (2010) Thermal acclimation of photosynthesis: a comparison of boreal and temperate tree species along a latitudinal transect. Plant, Cell \& Environment, 33, 888-899.

Esau K (1953) Plant Anatomy. John Wiley \& Sons Inc, New York.

Fonti P, Solomonoff N, Garcia-Gonzalez I (2007) Earlywood vessels of Castanea sativa record temperature before their formation. New Phytologist, 163, 562-570.

Garcia-Gonzalez I, Eckstein D (2003) Climatic signal of earlywood vessels of oak on a maritime site. Tree Physiology, 23, 497-504.

Gea-Izquierdo G, Fonti P, Cherubini P, Martin-Benito D, Chaar H, Canellas I (2012) Xylem hydraulic adjustment and growth response of Quercus canariensis Willd. to climatic variability. Tree Physiology, 32, 401-413.

Gea-Izquierdo G, Battipaglia G, Gaetner H, Cherubini P (2013) Xylem adjustment in Erica arborea to temperature and moisture availability in contrasting climates. IAWA, 34, 109-126.

Glass G, Peckham P, Sanders JR (1972) Consequences of failure to meet assumptions underlying the fixed effects analyses of variance and covariance. Review of Educational Research, 42, 237-288.

Hubbard RM, Ryan MG, Stiller V, Sperry JS (2001) Stomatal conductance and photosynthesis vary linearly with plant hydraulic conductance in ponderosa pine. Plant, Cell \& Environment, 24, 113-121.

Lachenbruch B, McCulloh KA (2014) Traits, properties, and performance: how woody plants combine hydraulic and mechanical functions in a cell, tissue, or whole plant. New Phytologist, 204, 747-764.

Luo Y, Chen H (2013) Observations from old forests underestimate climate change effects on tree mortality. Nature Communications, 4, 1655.

Luo Y, Chen H (2015) Climate change-associated tree mortality increases without decreasing water availability. Ecology Letters, 18, 1207-1215.

Ma Z, Peng C, Zhu Q et al. (2012) Regional drought-induced reduction in the biomass carbon sink of Canada's boreal forests. Proceedings of the National Academy of Sciences, 109, 2423-2427.

Maherali H, DeLucia EH (2000) Xylem conductivity and vulnerability to cavitation of ponderosa pine growing in contrasting climates. Tree Physiology, 20, 859-867.

Maherali H, DeLucia EH (2001) Influence of climate-driven shifts in biomass allocation on water transport and storage in ponderosa pine. Oecologia, 129, 481-491.

McCulloh KA, Johnson DM, Meinzer FC, Woodruff DR (2014) The dynamic pipeline: hydraulic capacitance and xylem hydraulic safety in four tall conifer species. Plant, Cell E Environment, 37, 1171-1183

Meinzer FC, Grantz DA, Goldstein G, Saliendra NZ (1990) Leaf water relations and maintenance of gas exchange in coffee cultivars grown in drying soil. Plant Physiology, 94, 1781-1787.

Meinzer FC, James SA, Goldstein G, Woodruff D (2003) Whole-tree water transport scales with sapwood capacitance in tropical forest canopy trees. Plant, Cell \& Environment, 26, 1147-1155.

Meinzer FC, Campanello PI, Domec J-C, Gatti MG, Goldstein G, Villalobos-Vega R, Woodruff DR (2008) Constraints on physiological function associated with branch architecture and wood density in tropical forest trees. Tree Physiology, 28, 1609-1617.

Melillo JM, Terese R, Yohe GW (eds.) (2014) Climate change impacts in the United States: The Third National Climate Assessment. U.S, Global Change Research Program, Washington, DC. 841 pp.

Mencuccini M (2003) The ecological significance of long-distance water transport: short-term regulation, long-term acclimation and the hydraulic costs of stature across plant life forms. Plant, Cell \& Environment, 26, 163-182.

Mencuccini M, Bonosi L (2001) Leaf/sapwood area ratios in Scots pine show acclimation across Europe. Canadian Journal of Forest Research, 31, 442-456.

Mencuccini M, Grace J (1995) Climate influences the leaf area/sapwood area ratio in Scots pine. Tree Physiology, 15, 1-10.

Moyes AB, Germino MJ, Kueppers LM (2015) Moisture rivals temperature in limiting photosynthesis by trees establishing beyond their cold-edge range limit under ambient and warmed conditions. New Phytologist, 207, 1005-1014.

Pfautsch S, Harbusch M, Wesolowski A et al. (2016) Climate determines vascular traits in the ecologically diverse genus Eucalyptus. Ecology Letters, 19, 240-248.

Phillips NG, Attard RD, Ghannoum O, Lewis JD, Logan BA, Tissue DT (2011) Impact of variable $\left[\mathrm{CO}_{2}\right]$ and temperature on water transport structure-function relationships in Eucalyptus. Tree Physiology, 31, 945-952.
Pittermann J, Sperry JS, Wheeler JK, Hacke UG, Sikkema EH (2006) Mechanical reinforcement of tracheids compromises the hydraulic efficiency of conifer xylem. Plant, Cell \& Environment, 29, 1618-1628.

Reich PB, Oleksyn J (2008) Climate warming will reduce growth and survival of Scots pine except in the far north. Ecology Letters, 11, 588-597.

Reich PB, Sendall KM, Rice K, Rich RL, Stefanski A, Hobbie SE, Montgomery RA (2015) Geographic range predicts photosynthetic and growth response to warming in co-occurring tree species. Nature Climate Change, 5, 148-152.

Reich PB, Sendall KM, Stefanski A, Wei X, Rich RL, Montgomery RA (2016) Boreal and temperate trees show strong respiratory acclimation to experimental and seasonal warming. Nature, 531, 633-636.

Rich RL, Stefanski A, Montgomery RA, Hobbie SE, Kimball B, Reich PB (2015) Design and performance of combined infrared canopy and belowground warming in the B4WarmED (Boreal Forest Warming at an Ecotone in Danger) experiment. Global Change Biology, 21, 2334-2348.

Sendall KM, Reich PB, Zhao C et al. (2015) Acclimation of photosynthetic temperature optima of temperate and boreal tree species in response to experimental forest warming. Global Change Biology, 21, 1342-1357.

Sherwood S, Fu Q (2014) A drier future? Science, 343, 737-739.

Team RD (2014) RStudio: Integrated Development for R. Available at: http:// www.RStudio.com/ide (accessed 5 July 2015).

Teskey RO, Will RE (1999) Acclimation of loblolly pine (Pinus taeda) seedlings to high temperature. Tree Physiology, 19, 519-525.

Thomas DS, Montagu KD, Conroy JP (2004) Changes in wood density of Eucalyptus camaldulensis due to temperature - the physiological link between water viscosity and wood anatomy. Forest Ecology and Management, 193, 157-165.

Thomas DS, Montagu KD, Conroy JP (2007) Temperature effects on wood anatomy, wood density, photosynthesis and biomass partitioning of Eucalyptus grandis seedlings. Tree Physiology, 27, 251-260.

Tjoelker MG, Oleksyn J, Reich PB (1998) Seedlings of five boreal tree seedlings differ in acclimation of photosynthesis to elevated $\mathrm{CO}_{2}$ and temperature. Tree Physiology, 18, 715-726.

Tyree MT, Zimmermann MH (2002) Xylem Structure and the Ascent of Sap, 2nd edn. Springer-Verlag, Berlin, Heidelberg, New York.

Voelker SL, Noirot-Cosson P-E, Stambaugh MC, McMurry ER, Meinzer FC, Lachenbruch B, Guyette RP (2012) Spring temperature responses of oaks are synchronous with North Atlantic conditions during the last deglaciation. Ecological Monographs, 82, 169-187.

Warton DI, Wright IJ, Falster DS, Westoby M (2006) Bivariate line-fitting methods for allometry. Biological Reviews, 81, 259-291

Way DA, Oren R (2010) Differential responses to changes in growth temperature between trees from different functional groups and biomes: a review and synthesis of data. Tree Physiology, 30, 669-688.

Way DA, Domec J-C, Jackson RB (2013) Elevated growth temperatures alter hydraulic characteristics in trembling aspen (Populus tremuloides) seedlings: implications for tree drought tolerance. Plant, Cell \& Environment, 36, 103-115.

Wertin TM, McGuire MA, Teskey RO (2011) Higher growth temperatures decreased net carbon assimilation and biomass accumulation of northern red oak seedlings near the southern limit of the species range. Tree Physiology, 31, 1277-1288.

\section{Supporting Information}

Additional Supporting Information may be found in the online version of this article:

Table S1. Species, site, temperature treatment, height, and diameter $5 \mathrm{~cm}$ above the ground for sampled saplings. Values shown are means (SE).

Table S2. Results from a mixed effect ANOVA analysis of hydraulically-weighted conduit diameter.

Table S3. Results from a mixed effect ANOVA analysis of sapwood capacitance values.

Table S4. Results from a mixed effect ANOVA analysis of wood density values. 